\title{
Inventory Model with Inflation under Credit Period and Shortage
}

\author{
Anjali Harit, Anurag Sharma, S.R. Singh
}

\begin{abstract}
In this study, an deterministic inventory model based on the concept of permissible delay in payments is discussed. Demand is assumed to be price dependent, and a constant price function represents it. Shortages are allowed and partially backlogged. In the realistic environment, it observed that there are several items like dry fruits, vegetables, grocery, and fruits, etc. which deteriorate after a time gap. So this model is also based on non-instantaneous deterioration. This study aims is to optimize the optimal order level and selling price to maximize the retailer`s total profit. Finally, numerical examples solved by using a proposed algorithm to show the validity of the model and sensitivity analysis done on parameters..
\end{abstract}

Keywords: Inventory, Price-dependent Demand, Noninstantaneous deterioration, Inflation, Trade credit, Shortage Backordering.

\section{INTRODUCTION}

$\mathrm{F}_{\text {or many years, a lot of work has published based on }}$ controlling inventory of deteriorating items. Deteriorating are theproducts which are spoilage with some period. Based on the decaying item first inventory model was published by[1]. They developed a simple inventory model based on economic order quantity with a constant rate ofdecaying items. In the realist environment concept of deterioration does not work because there are some items likefurniture, grocery, clothes, and vice versa are not get decaying instantaneously. This phenomenon is known as non-instantaneous deterioration. Considering this concept [2]developed the first inventory model onstock dependent demand and shortage withnon-instantaneous deterioration items, which partially backlogged. An inventory model on especially for a manufacturer where manufactured productnot only deteriorates but also has a maximum lifetime is developed by [3]. Inflation is the increase in the general price level of goods and services. The idea ofinflation is first introduced by[4]. Inflation is an essential aspect of the market. In this paper, we also consider inflation to find total cost so that value ofmoney will not affect optimal profit. In the business practice, it assumed that the customer pays for the purchased items asthey received from the vendor. In practice, the vendor allows the customer to settle the account with some delay period.This contract of delay in giving payment is known as trade credit. This phenomenon provides a very fruitful result to themerchants. Such an arrangement

Revised Manuscript Received on June 22, 2020.

* Correspondence Author

Anjali Harit*, Department of Mathematics, D.N. College, Meerut, India. Email: anjaliharit408@gmail.com

Anurag Sharma, Department of Mathematics, D.N. College, Meerut, India. Email: sharmaadr@gmail.com

S. R. Singh, department of mathematics, C. C. S. University, Meerut, Uttar Pradesh, India. Email: shivrajpundir@gmail.com has attracted the interest of so many researchers and practitioners in recent years. Thefirst paper using this concept was published by [5]. [6]discussed an inventory model onthe EOQ model with permissible delay in time. The concept of discounted cash flow(DCF) approach was first introducedby [7]. They presented a DCF approach for trade credit with an economic ordering policy fordeteriorating items. A generalization of[7] model done by [8]by introducing concept ofdeteriorating item with trade credit linked to order quantity. [9]discussed the impact of trade credit on vendor and buyerconsidering and also the effect of items of imperfect quality. [3] discussed the effect on inflation on trade credit policy under fuzzy environment. [10]proposed an inventory model based on price dependent demand. [11] developed a model in which they considered trade creditand replenishment decisions on default risk. [12] proposed amodel on trade credit they choose asymmetric credit default risk which is divided into three parts they are screening,checking or insurance. By considering existing literature on trade credit, this study is based on an inventory model usingprice-dependent demand, non-instantaneous deteriorating items, and credit policy under the effect of inflation. Shortagesare allowed and partially backlogged. The objective of this study is to determine the retailer\& optimal replenishmentpolicies that maximize total optimal profit/time(unit). The paper organized as section 2 defines the assumptions andnotation used throughout the article. Section 3 describes the inventory model and then establishes the retailer\& annual totalprofit function of the system. Part 4 discusses the proposed inventory model with numerical examples, and a sensitivityanalysis presented in part 5 . Finally, Section 6 discuss the conclusion of thepaper.

\section{ASSUMPTIONS AND NOTATIONS}

The assumptions used to develop the mathematical modelling:

- Replenishment rate is instantaneous

- Lead-time is negligible.

- The planning horizon of the inventory system is infinite.

- The demand rate is price dependent i.e. $\mathrm{D}(\mathrm{p})$ = a-bp.

- Rate of production is greater than the demand rate.

- Unsatisfied demand/ shortages are allowed. 


\section{Inventory Model with Inflation under Credit Period and Shortage}

The following notations are used to develop the model is same as used in [13]:

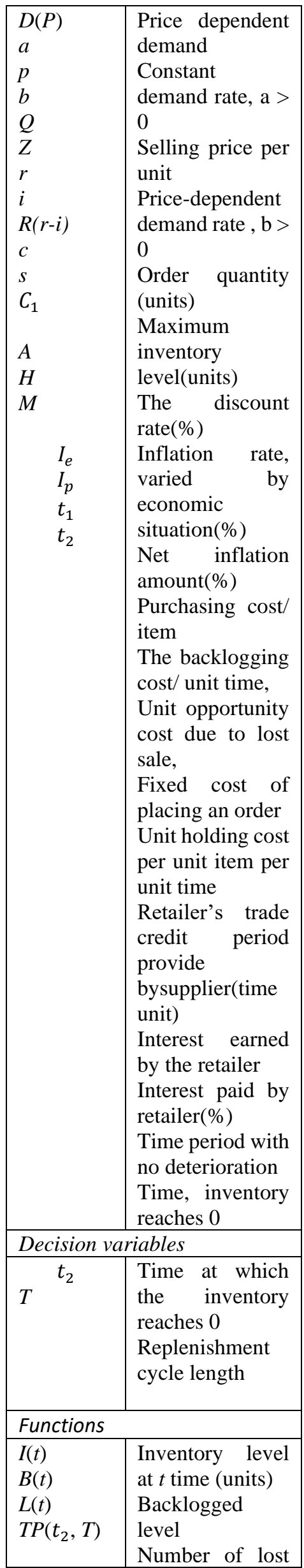

\begin{tabular}{|c|c|}
\hline & $\begin{array}{l}\text { sales,(units) } \\
\text { Total relevant } \\
\text { profit/unittime }\end{array}$ \\
\hline \multicolumn{2}{|c|}{ Optimal values } \\
\hline $\begin{array}{l}T \\
\mathrm{~T} P^{*}\left(t_{2}, T\right)\end{array}$ & $\begin{array}{l}\text { Optimal time at } \\
\text { which the } \\
\text { inventory level } \\
\text { reaches } 0 \\
\text { Optimal length } \\
\text { of inventory } \\
\text { cycle } \\
\text { Optimal total } \\
\text { profit/time }\end{array}$ \\
\hline
\end{tabular}

\section{MATHEMATICAL MODELLING}

In this model, we discuss the modelling for non-declining items with shortage which is partially backlogged. $Q$ units lot size enters in the system. The items in lot assumed as they are not instantaneously deteriorating. Therefore, after time $t_{1}$, the items get deteriorate. In interval $\left[0, t_{1}\right]$ the inventory decreases due to demand only. During $\left[t_{1}, t_{2}\right]$ stock reaches 0 because of demand and declining of items. After that, during $\left[t_{2}, \mathrm{~T}\right]$, shortage start and partially backlogged. From $Q$ units a portion of $B$ units utilized to satisfy the shortage in demand from the last cycle, after that $Z$ units are left for the thenew inventory cycle. The behavior of the model for the cyclein [0, $T]$ is represented graphically with the help of Fig. 1.

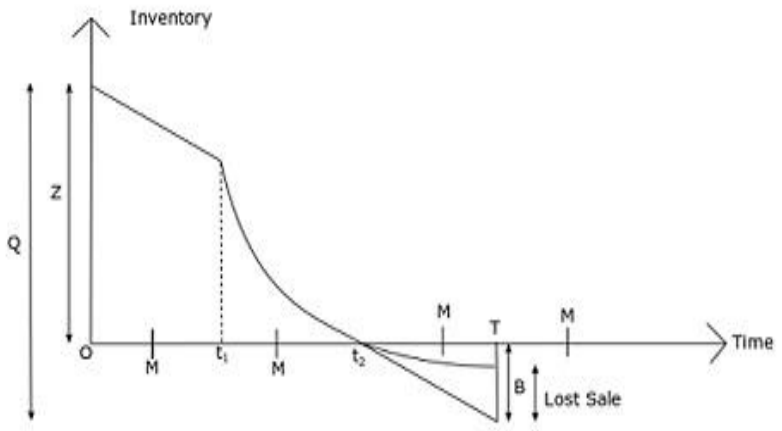

. Fig. 1. Graphical representation for all case of credit period $(M)$

Therefore, the differential equations that describe theinventory level at any time $t$ over the period $(0, T)$ are given by

$$
\begin{gathered}
\frac{d I(t)}{d t}=-(a-b p), 0 \leq t \leq t_{1}(1) \\
\frac{d I(t)}{d t}+\theta I(t)=-(a-b p), t_{1} \leq t \leq t_{2}(2) \\
\frac{d B(t)}{d t}=-(a-b p) e^{-v(T-t)}, t_{2} \leq t \leq T(3)
\end{gathered}
$$

And the boundary conditionare $I(0)=Z, I\left(t_{2}\right)=0, B\left(t_{2}\right)=0$ By solving (1), (2) and (3) using boundary conditions are:

$$
\begin{gathered}
I(t)=Z-(a-b p) t, 0 \leq t \leq t_{1} \\
I(t)=\frac{(a-b p)}{\theta}\left(e^{\theta\left(t_{2}-t\right)}-1\right), t_{1} \leq t \leq t_{2} \\
B(t)=\frac{a-b p}{\theta}\left(e^{-v(T-t)}-e^{-v\left(T-t_{2}\right)}\right), t_{2} \leq t \leq T
\end{gathered}
$$


The number of lost sales is

$L(t)=\int_{t_{2}}^{T}(a-b p)\left(1-e^{-v(T-t)}\right) d t$

$=(a-b p)\left[\left(t-t_{2}\right)-\frac{1}{v}\left(e^{-v(T-t)}-e^{-v\left(T-t_{2}\right)}\right)\right]$

Considering continuity of $\mathrm{I}(\mathrm{t})$ at $t=t_{1}$, it follows from (4) and (5) that

$(a-b p) t_{1}=\frac{(a-b p)}{\theta}\left(e^{\theta\left(t_{2}-t_{1}\right)}-1\right)(8$

Which implies that the maximum inventory level per cycle is

$$
Z=(a-b p) t_{1}+\frac{(a-b p)}{\theta}\left(e^{\theta\left(t_{2}-t_{1}\right)}-1\right)
$$

Now, replacet by $T$ in (6), the maximum amount of backlogged demand is

$$
B=\frac{(a-b p)}{v}\left(1-e^{-v\left(T-t_{2}\right)}\right)
$$

Order quantity over the replenishment cycle is

$$
\begin{aligned}
& Q=Z+B(t)=(a-b p) t_{1}+\frac{(a-b p)}{\theta}\left(e^{\theta\left(t_{2}-t_{1}\right)}-1\right) \\
& +\frac{(a-b p)}{v}\left(1-e^{-v\left(T-t_{2}\right)}\right)(11)
\end{aligned}
$$

Thus the present worth of the total profit per cycle for the inventory system consists of the following components, which are calculated using DCF approach, as follows:

1) Replenishment cost is $A$

2) Holding cost

$$
\begin{aligned}
& =H\left(\int_{0}^{t_{1}} I(t) e^{-R t} d t+\int_{t_{1}}^{t_{2}} I(t) e^{-R t} d t\right) \\
& =H\left[\frac{Z}{R}-\frac{1}{R}\left(Z-(a-b p) t_{1}+\frac{(a-b p)}{\theta}\left(e^{\theta\left(t_{2}-t_{1}\right)}-1\right) t_{1}\right) e^{-R t_{1}}\right. \\
& +\frac{1}{R^{2}}\left((a-b p) t_{1}+\frac{(a-b p)}{\theta}\left(e^{\theta\left(t_{2}-t_{1}\right)}-1\right)\left(e^{-R t_{1}}-1\right)\right. \\
& +\frac{(a-b p)}{\theta}\left(-\frac{1}{\theta}\left(e^{-R t_{2}}-e^{-\theta t_{2}-(\theta+R) t_{1}}\right)\right. \\
& \left.\left.+\frac{1}{R}\left(e^{R t_{2}}-e^{-R t_{1}}\right)\right)\right]
\end{aligned}
$$

3) Backlogging cost is $s \int_{t_{2}}^{T} B(t) e^{-R t} d t$

$$
\begin{aligned}
& =\frac{s(a-b p)}{v} e^{-v T}\left[\frac{1}{v-R}\left(e^{(v-R) T}-e^{(v-R) t_{2}}\right)\right. \\
& \left.+\frac{e^{v t_{2}}}{R}\left(e^{-R T}-e^{-R t_{2}}\right)\right]
\end{aligned}
$$

4) Purchasing cost is $c Q e^{-R M}$

$$
\begin{aligned}
& =c e^{-R M}\left[(a-b p) t_{1}+\frac{(a-b p)}{\theta}\left(e^{\theta\left(t_{2}-t_{1}\right)}-1\right)\right. \\
& \left.+\frac{(a-b p)}{v}\left(1-e^{-v\left(T-t_{2}\right)}\right)\right]
\end{aligned}
$$

5) Revenue amount is

$$
\begin{aligned}
& \mathrm{p}\left\{\int_{0}^{t_{2}}(a-b p) e^{-R t} d t+B(t) e^{-R t}\right\} \\
& \quad=p(a-b p)\left\{\frac{1}{R}\left(1-e^{-R t_{2}}\right)+\frac{e^{-R T}}{v}\left(1-e^{v\left(T-t_{2}\right)}\right)\right\}
\end{aligned}
$$

\section{A. Interest earned and interest paid}

The interest earned, interest paid and profit functions are computed as:
Case $1-0<M \leq t_{1}<t_{2}$

Case $2-0<t_{1}<M \leq t_{2}$

Case $-0<t_{1}<t_{2}<M \leq T$

Case $4-0<t_{1}<t_{2}<T \leq M$

Case 1:0 $<M \leq t_{1}<t_{2}$

In this case the interest earned is calculated in two parts:

Part 1: Interest earned by satisfying the shortages is:

Interest earned is $=\mathrm{p} I_{e} \int_{0}^{M} B(T) e^{-R t} d t$

$$
=p I_{e} \frac{(a-b p)}{v R}\left(1-e^{-R M}\right)\left(1-e^{-v\left(T-t_{2}\right)}\right)
$$

Part 2: Interest earned from 0 to $M$ is:

Interest earned $=p I_{e} \int_{0}^{M}(a-b p) t e^{-R t} d t$

$=p I_{e} \frac{(a-b p)}{R}\left[\frac{1}{R}\left(1-e^{-R M}\right)-M e^{-R M}\right]$

Total interest earned

$$
\begin{aligned}
& =p I_{e}\left[\frac{(a-b p)}{v R}\left(1-e^{-R M}\right)\left(1-e^{-v\left(T-t_{2}\right)}\right)\right. \\
& \left.+\frac{(a-b p)}{R}\left(\frac{1}{R}\left(1-e^{-R M}\right)-M e^{-R M}\right)\right]
\end{aligned}
$$

Further, the interest payable from $\mathrm{M}$ to

$t_{2}=c I_{p}\left\{\int_{M}^{t_{1}} Z e^{-R t} d t+\int_{t_{1}}^{t_{2}} I(t) e^{-R t} d t\right\}$

$$
=c I_{p}\left\{\frac{Z}{R}\left(e^{-R M}-e^{-R t_{1}}\right)+\frac{(a-b p)}{\theta}\left[-\frac{1}{\theta+R}\left(e^{-R t_{2}}\right.\right.\right.
$$

$\left.\left.-e^{-\theta\left(t_{2}-t_{1}\right)}+\frac{1}{R}\left(e^{-R t_{2}}-e^{-R t_{1}}\right)\right]\right\}$

Case 2: $0<t_{1}<M \leq t_{2}<T$

The interest earned is equivalent to previous case 1 .

Part 1:Interest payable from $M$ to $t_{2}$

$$
\begin{aligned}
& =c I_{p}\left\{\int_{M}^{t_{2}} I(t) e^{-R t} d t\right\} \\
& =c I_{p} \frac{(a-b p)}{\theta}\left\{\frac{1}{\theta+R}\left[e^{\theta t_{2}-(\theta+R) M}-e^{-R t_{2}}\right]\right. \\
& \left.+\frac{1}{R}\left(e^{-R t_{2}}-e^{-R M}\right)\right\}
\end{aligned}
$$

Case 3: $0<t_{1}<t_{2}<M \leq T$

The interest earned is calculated as follows:

Part 1: Interest earned at the beginning of the cycle i.e.

$=p I_{e}\left\{\int_{0}^{M} B(T) e^{-R t} d t\right.$

$=p I_{e}\left\{\frac{(a-b p)}{R v}\left(1-e^{-R M}\right)\left(1-e^{-v\left(T-t_{2}\right)}\right)\right\}$

Part 2: Interest earned from 0 to $t_{2}$,

$=p I_{e}\left(\int_{0}^{t_{2}} D t e^{-R t} d t\right)$

$=p I_{e} \frac{(a-b p)}{R}\left(\frac{1}{R}\left(1-e^{-R t_{2}}\right)-t_{2} e^{-R t_{2}}\right)$

Part 3: The interest earned on the revenue of sales till $t_{2}$, for the time period $\left(t_{2}, M\right)$

$=p I_{e}\left\{\int_{t_{2}}^{M}\left(\int_{0}^{t_{2}}(a-b p) d t\right) e^{-R t} d t\right\}$

$=p I_{e} \frac{(a-b p) t_{2}}{R}\left(e^{-R t_{2}}-e^{-R M}\right)$

Totalinterest earned 


\section{Inventory Model with Inflation under Credit Period and Shortage}

$$
\begin{gathered}
=\operatorname{lI}_{e}\left\{\frac{(a-b p)}{R v}\left(1-e^{-R M}\right)\left(1-e^{-v\left(T-t_{2}\right)}\right)\right. \\
+\frac{(a-b p)}{R}\left(\frac{1}{R}\left(1-e^{-R t_{2}}\right)-t_{2} e^{-R t_{2}}\right) \\
\left.+\frac{(a-b p) t_{2}}{R}\left(e^{-R t_{2}}-e^{-R M}\right)\right\}
\end{gathered}
$$

In this case no interest paid.

Case 4: $0<t_{1}<t_{2}<T \leq M$

Interest earned and interest paid in this case is similar as in case 3 .

\section{B. Retailer`s total profit}

Therefore, the present worth of total profit per unit time during the cycle $(0, \mathrm{~T})$ is given by

$\mathrm{TP}\left(t_{1}, T\right)=\frac{1}{T}[$ Sales revenue - Ordering cost - Holding cost -

Purchasing cost + Interest earned - Interest paid]

The total profit/ unit time is

$$
\begin{gathered}
T P\left(t_{2}, T\right)=\left\{\begin{array}{l}
T P_{1}\left(t_{2}, T\right) \text { if } 0<M \leq t_{1}<t_{2}<T \\
T P_{2}\left(t_{2}, T\right) \text { if } 0<t_{1}<M \leq t_{2}<T \\
T P_{3}\left(t_{2}, T\right) \text { if } 0<t_{1}<t_{2}<M \leq T \\
T P_{4}\left(t_{2}, T\right) \text { if } 0<t_{1}<t_{2}<T \leq M
\end{array}\right. \\
T P_{1}\left(t_{2}, T\right)=\frac{p(a-b p)}{T}\left[\frac{1}{R}\left(1-e^{-R t_{2}}\right)+\frac{e^{-R T}}{v}\left(1-e^{v\left(T-t_{2}\right)}\right)\right] \\
-\frac{A}{T}-\frac{H}{T}\left[\frac{Z}{R}-\frac{\left(Z-(a-b p) t_{1}\right)}{R} e^{-R t_{1}}+\frac{(a-b p)}{R^{2}}\left(e^{-R t_{1}}-1\right)\right. \\
+\frac{(a-b p)}{\theta}\left[-\frac{1}{\theta+R}\left(e^{-R t_{2}}-e^{-\theta t_{2}-(\theta+R) t_{1}}\right)+\frac{1}{R}\left(e^{-R t_{2}}\right.\right. \\
\left.\left.\left.-e^{-R t_{1}}\right)\right]\right]-c e^{-R M}\left[(a-b p) t_{1}+\frac{(a-b p)}{\theta}\left(e^{\theta\left(t_{2}-t_{1}\right)}-1\right)\right. \\
+\frac{(a-b p)}{v}\left(1-e^{-v\left(T-t_{2}\right)}\right)+p I_{e} \frac{(a-b p)}{R}\left[\frac{1}{v}\left(1-e^{-R M}\right)(1\right. \\
\left.\left.-e^{-v\left(T-t_{2}\right)}\right)+\frac{1}{R}\left(1-e^{-R M}\right)-M e^{-R M}\right]-c I_{P}\left[\frac { Z } { R } \left(e^{-R M}\right.\right. \\
\left.-e^{-R t_{1}}\right)+\frac{(a-b p)}{\theta}\left[-\frac{1}{\theta+R}\left(e^{-R t_{2}}-e^{-\theta\left(t_{2}-t_{1}\right)}\right)\right. \\
\left.+\frac{1}{R}\left(e^{-R t_{2}}-e^{R t_{1}}\right)\right]
\end{gathered}
$$$$
T P_{2}\left(t_{2}, T\right)=\frac{p(a-b p)}{T}\left[\frac{1}{R}\left(1-e^{-R t_{2}}\right)+\frac{e^{-R T}}{v}\left(1-e^{v\left(T-t_{2}\right)}\right)\right]
$$$$
-\frac{A}{T}-\frac{H}{T}\left[\frac{Z}{R}-\frac{\left(Z-(a-b p) t_{1}\right)}{R} e^{-R t_{1}}+\frac{(a-b p)}{R^{2}}\left(e^{-R t_{1}}-1\right)\right.
$$$$
+\frac{(a-b p)}{\theta}\left[-\frac{1}{\theta+R}\left(e^{-R t_{2}}-e^{-\theta t_{2}-(\theta+R) t_{1}}\right)+\frac{1}{R}\left(e^{-R t_{2}}\right.\right.
$$$$
\left.\left.\left.-e^{-R t_{1}}\right)\right]\right]-c e^{-R M}\left[(a-b p) t_{1}+\frac{(a-b p)}{\theta}\left(e^{\theta\left(t_{2}-t_{1}\right)}-1\right)\right.
$$$$
+\frac{(a-b p)}{v}\left(1-e^{-v\left(T-t_{2}\right)}\right)+p I_{e} \frac{(a-b p)}{R}\left[\frac{1}{v}\left(1-e^{-R M}\right)(1\right.
$$$$
\left.\left.-e^{-v\left(T-t_{2}\right)}\right)+\frac{1}{R}\left(1-e^{-R M}\right)-M e^{-R M}\right]-c I_{p} \frac{(a-b p)}{\theta}
$$$$
\left\{\frac{1}{\theta+R}\left[e^{\theta t_{2}-(\theta+R) M}-e^{-R t_{2}}\right]+\frac{1}{R}\left(e^{-R t_{2}}-e^{-R M}\right)\right\}
$$

$$
\begin{aligned}
& \mathrm{TP}_{3}\left(t_{2}, T\right)=T P_{4}\left(t_{2}, T\right)=\frac{p(a-b p)}{T}\left[\frac{1}{R}\left(1-e^{-R t_{2}}\right)+\frac{e^{-R T}}{v}\left(1-e^{v\left(T-t_{2}\right)}\right)\right] \\
& -\frac{A}{T}-\frac{H}{T}\left[\frac{Z}{R}-\frac{\left(Z-(a-b p) t_{1}\right)}{R} e^{-R t_{1}}+\frac{(a-b p)}{R^{2}}\left(e^{-R t_{1}}-1\right)\right. \\
& +\frac{(a-b p)}{\theta}\left[-\frac{1}{\theta+R}\left(e^{-R t_{2}}-e^{-\theta t_{2}-(\theta+R) t_{1}}\right)+\frac{1}{R}\left(e^{-R t_{2}}\right.\right. \\
& \left.\left.\left.-e^{-R t_{1}}\right)\right]\right]-c e^{-R M}\left[(a-b p) t_{1}+\frac{(a-b p)}{\theta}\left(e^{\theta\left(t_{2}-t_{1}\right)}-1\right)\right. \\
& +\frac{(a-b p)}{v}\left(1-e^{-v\left(T-t_{2}\right)}\right)+p I_{e}\left\{\frac{(a-b p)}{R v}\left(1-e^{-R M}\right)(1\right. \\
& \left.-e^{-v\left(T-t_{2}\right)}\right)+\frac{(a-b p)}{R}\left(\frac{1}{R}\left(1-e^{-R t_{2}}\right)-t_{2} e^{-R t_{2}}\right) \\
& \left.+p I_{e} \frac{(a-b p) t_{2}}{R}\left(e^{-R t_{2}}-e^{-R M}\right)\right\}
\end{aligned}
$$

\section{Optimality of the profit equations function}

Now, discuss the optimal solution of the objective function. The necessary conditions for the total profit to be maximum are

$$
\frac{\partial T P_{i}\left(t_{2}, T\right)}{\partial t_{2}}=0 \text { and } \frac{\partial T P_{i}\left(t_{2}, T\right)}{\partial T}=0 \text {; for } i=1,2,3 \text { and } 4 \text { (24) }
$$

The sufficient conditions for maximizing $T P_{i}\left(t_{2}, T\right)$ by using second order partial derivatives are

$\frac{\partial^{2} T P_{i}\left(t_{2}, T\right)}{\partial t_{2}^{2}}>0$, and $\frac{\partial^{2} T P_{i}\left(t_{2}, T\right)}{\partial T^{2}}>0$; for $\mathrm{i}=1$,2,3and4 (25)

The objective of the present model is to obtain the optimal values of $t_{2}$ and $T$ so as to maximize the total profit function. Since it is difficult to solve the optimality condition of the profit function mathematically, the convexity total profit functions has established graphically (Figs. 2-4) by using Mathematica software. Hence, the final optimal solution is unique one.

\section{Special cases}

The proposed model is general inventorymodel. In this section, we discuss some special cases that present inventory model contains.

a. When $t_{1}=0, v \rightarrow \infty$ and $R=0$, then proposed model is same as [14].

b. When $\theta=0, t_{1}=0, v \rightarrow \infty$ and $R=0$, then proposed model same as[15].

c. When $t_{1}=0$, and complete backlogged, $M=0$, and $I_{e}=$ 0 , then proposed model is same as [16]

d. When $t_{1}=0, v \rightarrow \infty, M=0$, and $I_{e}=0$, then proposed model is same as[1].

e. When $\theta=0, t_{1}=0, v \rightarrow \infty, \mathrm{M}=0, I_{e}=0$ and $I_{e}=0$ then proposed model is same as traditional economic order quantity inventory model with optimal quantity

$$
Q^{*}=\sqrt{\frac{2 A(a-b p)}{H}}
$$

\section{NUMERICAL EXAMPLE}

This section validate the developed inventory model with the numerical examples.

Example1: Consider an inventory system with the following data: 
$\mathrm{A}=250 /$ order, $C_{1}=5 /$ unit, $\mathrm{a}=3000$ unit/year, $\mathrm{R}=0.06$, $\mathrm{c}=4 /$ unit $I_{p}=0.15 /$ year, $\mathrm{p}=15 /$ unit, $I_{e}=0.12 /$ year, $\mathrm{H}=0.5 /$ unit/year, $t_{1}=0.2$, $\mathrm{W}=$ 200units, $\theta=0.05 /$ unit $\mathrm{s}=4 /$ unit/year, $\mathrm{M}=0.25$ year. $\mathrm{v}=0.7 /$ unit,$t_{2}=0.593$ year, $\mathrm{T}=0.875$ year, $\mathrm{Q}=1982.67$ units and $\mathrm{TP}^{*}=4056.45$ with suitable units. Fig. 2 shows convexity function graphically.

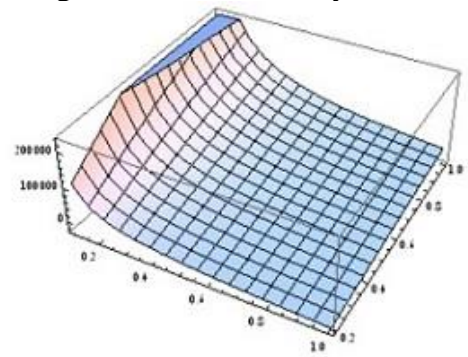

Fig. 2. Convexity of TP* versus $t_{2}$ and T

Example2: Consider an inventory system with the following data:

$\mathrm{A}=250 /$ order, $C_{1}=5 /$ unit,

$\mathrm{a}=3000$ unit/year, $\mathrm{R}=0.06$,

$\mathrm{c}=4 /$ unit, $I_{p}=0.15 /$ year,

$\mathrm{p}=15 /$ unit, $I_{e}=0.12 /$ year,

$\mathrm{H}=0.5 /$ unit/year, $t_{1}=0.2$,

$\mathrm{W}=200$ units, $\theta=0.05 /$ unit

$\mathrm{s}=4 /$ unit/year, $t_{2}=0.613$ year,

$\mathrm{v}=0.9$ /unit, $\mathrm{M}=0.25$ year.

$\mathrm{T}=0.893$ year, $\mathrm{Q}=2039.04$, and $\mathrm{TP}^{*}=4900.63$ with suitable units. Fig. 3 shows convexity function graphically.

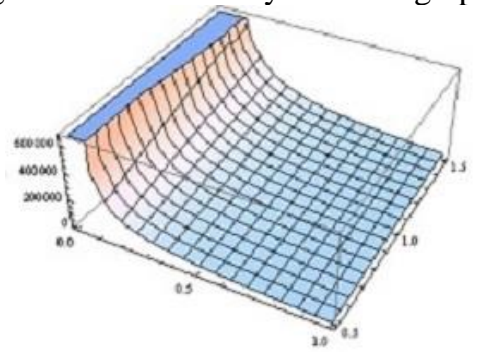

Fig. 3.Convexity of TP* versus $t_{2}$ and $T$

Example3: Consider an inventory system with the following data:

$\mathrm{A}=250 /$ order, $C_{1}=5 /$ unit,

$\mathrm{a}=3000 \mathrm{unit} /$ year, $\mathrm{R}=0.06$,

$\mathrm{c}=4 /$ unit, $I_{p}=0.15 /$ year,

$\mathrm{p}=15 /$ unit, $I_{e}=0.12 /$ year,

$\mathrm{H}=0.5 /$ unit/year, $t_{1}=0.2$,

$\mathrm{W}=$ 200units, $\theta=0.05 /$ unit

$\mathrm{s}=4 /$ unit $/$ year,$t_{2}=0.561$ year,

$\mathrm{v}=0.9$ /unit, $\mathrm{M}=0.25$ year.

$\mathrm{T}=0.859$ year, $\mathrm{Q}=1928.29$, and $\mathrm{TP}^{*}=6793.42$ with suitable units. Figure 4 shows convexity function graphically.

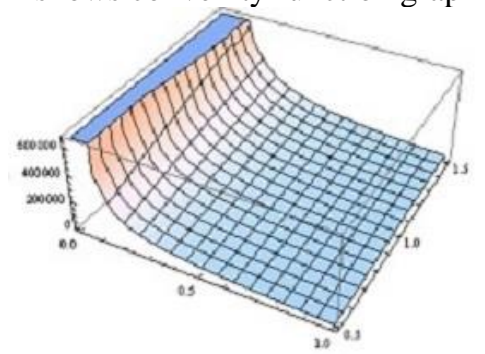

Fig. 4. Convexity of TP*versus $t_{2}$ and $T$

\section{SENSITIVITY ANALYSIS}

In this section, sensitivity analysis has been performed in order to study the impact of non-deteriorating period $\left(t_{1}\right)$; credit period $(\mathrm{M})$, inflation rate(R); interest $\operatorname{paid}\left(I_{p}\right)$ and interest earned $\left(I_{e}\right)$ on the lot size $\left(\mathrm{Q}^{*}\right)$, cycle length $(\mathrm{T})$ and the retailer's total optimal profit $\left(\mathrm{TP}^{*}\right)$. Sensitivity table is depends on numerical example 1 . Results summarized by tables 2-5 given below.

Table 2: Effect of non- deteriorating itemsand credit

period $\left(t_{1}\right.$ and $\left.M\right)$ on optimal replenishment policy

\begin{tabular}{|c|c|c|c|c|c|}
\hline $\boldsymbol{t}_{\mathbf{1}}$ & $\mathbf{M}$ & $\boldsymbol{t}_{\mathbf{2}}$ & $\boldsymbol{T}$ & $\boldsymbol{Q}$ & $\boldsymbol{T P}^{*}$ \\
\hline 0.2 & 0.15 & 0.593 & 0.735 & 1727.04 & 11964.6 \\
\hline & 0.25 & 0.613 & 0.753 & 1778.12 & 12665.1 \\
\hline & 0.35 & 0.631 & 0.771 & 1828.13 & 13509.3 \\
\hline 0.4 & 0.15 & 0.659 & 0.806 & 1831.97 & 13860.1 \\
\hline & 0.25 & 0.677 & 0.813 & 1856.49 & 15086.2 \\
\hline 0.6 & 0.35 & 0.695 & 0.829 & 1899.23 & 15814.3 \\
\hline & 0.25 & 0.716 & 0.857 & 1916.66 & 11654.1 \\
\hline & 0.35 & 0.789 & 0.894 & 2003.01 & 11773.3 \\
\hline
\end{tabular}

Table 3: Effect of $R$ on the optimal replenishment policy

\begin{tabular}{|c|c|c|c|c|}
\hline $\boldsymbol{R}$ & $\boldsymbol{t}_{\mathbf{1}}$ & $\mathbf{T}$ & $\mathbf{Q}$ & $\mathbf{T P *}$ \\
\hline 0.11 & 0.266 & 0.812 & 1990.07 & 10818.3 \\
\hline 0.09 & 0.296 & 0.853 & 2057.74 & 11374.1 \\
\hline 0.07 & 0.329 & 0.897 & 2126.71 & 12579.7 \\
\hline 0.05 & 0.367 & 0.935 & 2178.83 & 15410.2 \\
\hline 0.03 & 0.408 & 0.974 & 2230.09 & 20245.7 \\
\hline
\end{tabular}

Table 4: Effect of $v$ on optimal replenishment policy

\begin{tabular}{|c|c|c|c|c|}
\hline $\boldsymbol{V}$ & $\boldsymbol{t}_{\mathbf{2}}$ & $\boldsymbol{T}$ & $\boldsymbol{Q}$ & $\boldsymbol{T P}^{*}$ \\
\hline 0.3 & 0.349 & 0.862 & 1876.07 & 18290.8 \\
\hline 0.6 & 0.349 & 0.857 & 1844.02 & 18272.4 \\
\hline 0.9 & 0.349 & 0.852 & 1816.25 & 18253.7 \\
\hline 1.2 & 0.349 & 0.848 & 1795.37 & 18234.7 \\
\hline
\end{tabular}

Table 5: Effect of $I_{e}$ and $I_{p}$ on the optimal replenishment

\begin{tabular}{|c|c|c|c|c|c|}
\hline \multicolumn{1}{|c|}{ policy } \\
\hline $\boldsymbol{I}_{\boldsymbol{e}}$ & $\boldsymbol{I}_{\boldsymbol{p}}$ & $\boldsymbol{t}_{\mathbf{2}}$ & $\boldsymbol{T}$ & $\boldsymbol{Q}$ & $\boldsymbol{T P}^{*}$ \\
\hline 0.12 & 0.20 & 0.583 & 0.857 & 1946.16 & 3369.47 \\
\hline & 0.15 & 0.594 & 0.868 & 1976.22 & 4488.48 \\
\hline & 0.10 & 0.603 & 0.873 & 1993.88 & 5936.58 \\
\hline 0.17 & 0.20 & 0.584 & 0.858 & 1948.88 & 4022.01 \\
\hline & 0.15 & 0.595 & 0.869 & 1978.96 & 5141.02 \\
\hline 0.22 & 0.10 & 0.604 & 0.874 & 1996.64 & 6580.46 \\
\hline & 0.20 & 0.585 & 0.859 & 1951.61 & 4674.55 \\
\hline & 0.10 & 0.596 & 0.870 & 1981.70 & 5793.56 \\
\hline
\end{tabular}

Table 2 indicates that $T, Q$ and $T P$ increase as $M$ increase. It suggests that permissible delay in payments facilitates the business for each provider and retail merchant. In addition the extended credit amount (without penalty) for payment to the provider, indirectly reduced the prices incurred by the retailer and ultimately ends in higher profit. It specifies the positive influence of non-instantaneous deteriorating items within inventory modeling because the amount for deterioration $\left(t_{1}\right)$ will increase; the deterioration value for items decreases that accounts for more significant profits for the corporate. 


\section{Inventory Model with Inflation under Credit Period and Shortage}

Table 3 shows when $R$ decreases (i.e., the inflation rate is increasing), $Q$ and $T P$ increase. Since the cost of goods is high in an inflationary market, the retailer should place a large order for an extended interval to maintain the profit. Table 4 clearly shows that as $v$ increases, there is decrease in $T P, T$, and $Q$.As $Q$ decreases eventually results in less profit. Table 5 exhibits as $I_{e}$ increases, the order amount as well as the overall average profit increase. The total earnings increase in this state when considering that growing interest earned rates contribute to additional significant revenue. An assessment of this, while the $I_{p}$ prices increased outlets general average income decreases, as in this case, the interest charges get brought to general costs, which outcomesas diminishing profits.

\section{CONCLUSION}

In this study, we developed an model for permissible delay in payment under inflationary conditions and non-instantaneous deteriorating items. In contrast to previous studies, we characterized the concept of trade credit with price dependent demand under the effect of inflation to tackle the real situation in a more effective manner. This study will provide a profitable result for the business situation. Shortages are allowed in this study, which is fulfilled by a partial backlogging rate. This study controls the seller's optimal replenishment policies that maximize total optimal profit/ unit time. Sensitivity analysis based on numerical examples for key parameters has summarized to direct the management of the market establishments to take appropriate activity under the prevailing conditions. The study is more effective as it helps the decision-maker to provide a suitable framework to assess profitability.

\section{ACKNOWLEDGMENT}

The author would like to thank the anonymous referees for their helpful suggestions, which improved the presentation of this paper and also like to thank UGC for grant research fellowship.

\section{REFERENCES}

1. P. N. Ghare and G. F. Schrader, “A Model for Exponentially Decaying Inventories.," The Journal of Industrial Engineering, vol. 15, pp. 238-243, 1963.

2. K.-S. Wu, L.-Y. Ouyang, and C.-T. Yang, “An optimal replenishment policy for non-instantaneous deteriorating items with stock-dependent demand and partial backlogging," Int. J. Prod. Econ., vol. 101, no. 2, pp. 369-384, Jun. 2006, doi: 10.1016/j.ijpe.2005.01.010.

3. D. Yadav, S. R. Singh, and R. Kumari, "Retailer's optimal policy under inflation in fuzzy environment with trade credit," Int. J. Syst. Sci., vol. 46, no. 4, pp. 754-762, Mar. 2015, doi: 10.1080/00207721.2013.801094.

4. J. A. Buzacott, "Economic Order Quantities with Inflation," Oper. Res. Q. 1970-1977, vol. 26, no. 3, p. 553, Sep. 1975, doi: 10.2307/3008214.

5. C. W. Haley and R. C. Higgins, "Inventory Policy And TradeCredit Financing," INFORMS, vol. 20, no. 4, pp. 464-471, Jan. 1973.

6. S. K. Goyal, "Economic Order Quantity under Conditions of Permissible Delay in Payments," J. Oper. Res. Soc., vol. 36, no. 4, p. 335, Apr. 1985, doi: 10.2307/2582421.

7. C. K. Jaggi and S. P. Aggarwal, "Credit financing in economic ordering policies of deteriorating items," Int. J. Prod. Econ., vol. 34 no. 2, pp. 151-155, Mar. 1994, doi: 10.1016/0925-5273(94)90031-0.

8. K.-J. Chung and J.-J. Liao, "The optimal ordering policy in a DCF analysis for deteriorating items when trade credit depends on the order quantity," Int. J. Prod. Econ., vol. 100, no. 1, pp. 116-130, Mar. 2006, doi: 10.1016/j.ijpe.2004.10.011.

9. L.-H. Chen and F.-S. Kang, "Coordination between vendor and buyer considering trade credit and items of imperfect quality," Int. J. Prod.
Econ., vol. 123, no. 1, pp. 52-61, Jan. 2010, doi: 10.1016/j.ijpe.2009.06.043.

10. M. Rastogi, S. R. Singh, P. Kushwah, and S. Tayal, "Two warehouse inventory policy with price dependent demand and deterioration under partial backlogging," Decis. Sci. Lett., vol. 6, pp. 11-22, Jan. 2017, doi: 10.5267/j.dsl.2016.8.004.

11. Y.-C. Tsao, "Joint location, inventory, and preservation decisions for non-instantaneous deterioration items under delay in payments,' International Journal of Systems Science, vol. 47, no. 3, pp. 572-585, 2016.

12. H. Wang, C. Pan, Q. Wang, and P. Zhou, "Assessing sustainability performance of global supply chains: An input-output modeling approach,” Eur. J. Oper. Res., vol. 285, no. 1, pp. 393-404, Aug. 2020, doi: 10.1016/j.ejor.2020.01.057.

13. S. Tiwari, L. E. Cárdenas-Barrón, A. Khanna, and C. K. Jaggi, "Impact of trade credit and inflation on retailer's ordering policies for non-instantaneous deteriorating items in a two-warehouse environment," Int. J. Prod. Econ., vol. 176, pp. 154-169, Jun. 2016 , doi: 10.1016/j.ijpe.2016.03.016.

14. K.-J. Chung and T.-S. Huang, “The optimal retailer's ordering policies for deteriorating items with limited storage capacity under trade credit financing," Int. J. Prod. Econ., vol. 106, no. 1, pp. 127-145, Mar. 2007, doi: 10.1016/j.ijpe.2006.05.008.

15. S. P. Aggarwal and C. K. Jaggi, "Ordering Policies of Deteriorating Items under Permissible Delay in Payments," J. Oper. Res. Soc., vol. 46, no. 5, p. 658, May 1995, doi: $10.2307 / 2584538$.

16. T.-P. Hsieh, C.-Y. Dye, and L.-Y. Ouyang, "Determining optimal lot size for a two-warehouse system with deterioration and shortages using net present value," Eur. J. Oper. Res., vol. 191, no. 1, pp. 182-192, Nov. 2008, doi: 10.1016/j.ejor.2007.08.020.

\section{AUTHORS PROFILE}

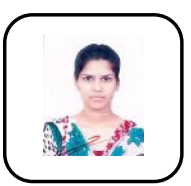

Anjali Harit received her M.Sc. degree in Mathematics from NAS college, Meerut India. He received her M.Phil. degree in Mathematics from Chaudhary Charan Singh University, Meerut, India. Her M.Phil. project report is on Cryptography. She is pursuing her Ph. D under the guidance of Anurag Sharma and S.R Singh in D. N. College, Meerut, India. Her research area is Inventory Control, Supply Chain Management, carbon Emission, Trade Credit, RFID, and Warehouse. She has published some research paper in reputed journal. She has communicated several research papers to journals of National and International repute

Anurag Sharmais currently working as an Associate

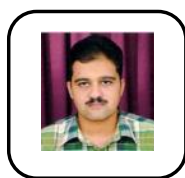

Professor in the department of mathematics, D.N. degree college, Meerut, India. He received his M.Sc.(Mathematics), M.Phil. degree(Mathematics) and hold his $\mathrm{Ph}$. D degree in inventory control from Chaudhary Charan Singh University, Meerut, India. His research area is Operation Research, Inventory control, Supply chain, Warehouse, Trade Credit. He published so many papers in reputed journal.

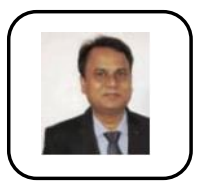

S.R. Singh is currently working as a Professor, Department of Mathematics, Chaudhary Charan Singh University, India. He got his MSc, MPhil and Ph.D. Degree in Mathematics from CCS University, Meerut. His research fields are Supply chain management, Inventory Management, and Production Problems. He has published his research papers in various reputed journals like International Journal of Operational Research, International Journal of Systems Science, , Asia Pacific Journal of Operational Research, Journal of Cleaner Production, Scientia Iranica, and other. Many scholars completed their Ph. D thesis under his supervision. 